This is an electronic reprint of the original article. This reprint may differ from the original in pagination and typographic detail.

Author(s): Virkkula, Tiina; Nikula, Tarja

Title: Identity construction in ELF contexts: a case study of Finnish engineering students working in Germany

Year: $\quad 2010$

Version:

Please cite the original version:

Virkkula, T., \& Nikula, T. (2010). Identity construction in ELF contexts: a case study of Finnish engineering students working in Germany. International Journal of Applied Linguistics, 20(2), 251-273. https://doi.org/10.1111/j.1473-4192.2009.00248.x

All material supplied via JYX is protected by copyright and other intellectual property rights, and duplication or sale of all or part of any of the repository collections is not permitted, except that material may be duplicated by you for your research use or educational purposes in electronic or print form. You must obtain permission for any other use. Electronic or print copies may not be offered, whether for sale or otherwise to anyone who is not an authorised user. 


\title{
Identity construction in ELF contexts: a case study of Finnish engineering students working in Germany
}

Tiina Virkkula and Tarja Nikula

University of Jyväskylä

\begin{abstract}
This paper explores connections between identity and language use in lingua franca contexts by investigating identity construction among Finnish English-as-a-lingua-franca users as revealed in interviews conducted both before and after a period spent abroad. The focus is on the users' own stories of their language use and learning and the discursive construction of identities. The study draws on poststructuralist theories on identity construction (e.g. Pavlenko and Blackledge 2004) and combines them with Norton's (2000) views on language learners' identity construction as well as Jenkins' (2007) and other scholars' conceptualizations of English as a lingua franca and its relationship to issues of identity. This article illustrates how language users actively draw on different discourses in constructing their identities as foreign language users.
\end{abstract}

Keywords: identity, English as a lingua franca, discourse analysis, interview, stay abroad

\section{Introduction}

Identity has in recent years attracted a great deal of attention in the social sciences. Overall, it is probably safe to argue that more traditional, essentialised notions of identity as a constant and single entity have given way to poststructuralist notions of identities as multiple, fluid, and negotiable (e.g. Hall 1996; Woodward 1997). Connections between identity and language have also been considered, often in multilingual and multicultural contexts (e.g. Le Page \& Tabouret-Keller 1985; Pavlenko \& Blackledge 2004). However, foreign or second language users' identities have received less attention and the topic has only recently started to attract more interest (for overviews, see Block 2007). Studies in this area have usually dealt with foreign language users' identities in contexts where the target language is used as a native language, and focused either on adult migrant contexts (e.g. Norton 2000; Block 2006) or on people studying abroad (Jackson 2008; Kinginger 2004; Polanyi 1995). Earlier studies have usually explored learner identities with the underlying assumption that the ultimate goal of language learning is to approximate as closely as possible to native speakers' skills in order to enter into social interaction with them. However, when considering English as the target language, it is important to bear in mind that it is commonly used as a lingua franca by speakers for whom it is not a native language. How identity features in such contexts has not been studied much (but see Jenkins 2007) but it is well worth exploring since acts of identification also occur in lingua franca contexts.

This paper focuses on the discursive identity construction of users of English as a lingua franca as revealed in interviews with Finnish engineering students that were 
conducted both before and after a period spent abroad. Briefly put, this study differs in one important respect from most studies on identity and second language learning and identity formation when staying abroad as it investigates identity construction in contexts where English is not the mother tongue but is used as a shared language by people from different countries. More specifically, the focus is on the users' own stories of their language use and language learning, i.e. on "the sense that is made of learning experiences" (Benson 2005:17) rather than on the situations of language use as such.

The study draws on poststructuralist theories of identity (e.g. Pavlenko and Blackledge 2004) and combines them with Norton's (2000) views on language learners' identity construction as well as Jenkins' (2007) and other scholars' conceptualizations of English as a lingua franca and its relationship to issues of identity. The article illustrates how language users draw on different discourses in constructing their identities as foreign language users. The participants in this study were seven Finnish engineering students who, as part of their studies, worked as industrial production workers in Germany for periods ranging from 4 to 6 months. The paper draws on and elaborates Virkkula's (2006) unpublished master's thesis and it will demonstrate that identity issues are relevant in lingua franca contexts where, through encounters with others, participants begin to see both the possibilities and constraints of their own language repertoires and hence begin to ascribe to new identity options that are different from those that are available in educational contexts.

\section{A discursive approach to identity}

Identity can be conceptualized in two fundamentally different ways: essentially and non-essentially. The essentialist view perceives identity as something connected to a person's self and considers it to be singular and rather stable. The non-essentialist view brings in the perspective of change, i.e. identity is unfinished, fluid, fragmented, multiple, constantly changing and transforming, and constructed across times, places, positions, practices and discourses (see e.g. Hall 1996; Woodward 1997).

This article approaches identity from a non-essentialist, discursive perspective, according to which identity is constructed in discourses and contexts and at different levels: individual, interactional and sociocultural-institutional (Pomerantz 2001). Language and discourses shape people but people also constantly shape discourses, constructing and negotiating their sense of themselves and their identities in interaction with others. Different identity options can be constructed, validated and offered through the discourses available to individuals at a particular point in time and place. (Davies and Harré 1990; Gergen 1999; Pavlenko and Blackledge 2004.) In this paper, our interest lies in exploring the discourses available to participants both before and after the internship in Germany.

In addition to identity, the core concepts that this article builds upon are discourse and subject position. In conceptualizing discourse, we draw on Hall (1996), Weedon (1997), Ivanić (1998), and Fairclough (2001, 2003), who approach discourse in broad terms as a way of representing ideas and knowledge. In essence, then, discourses represent certain 'takes' on the world that are manifested through language. Whenever people use language, they draw on pre-existing discourses to represent their conception of the world and of themselves. Language is therefore an important semiotic system through 
which discourses are realized. (Ivanić 1998: 17; Fairclough 2001: 235, 2003: 124; Weedon 1997: 34.)

Discourses allow for various subject positions. According to Davies and Harré (1990), subject positions are made available within a discourse as possibilities of defining oneself or attaching oneself to socially recognizable ways of being. The discourse of language education, for example, offers as available subject positions those of teacher and student. Subject positions hence serve as resources for identity construction. Hall (1996: 5-6), for example, maintains that identities are "points of temporary attachment to subject positions, which discursive practices construct for us". In this paper, our interest lies in exploring the kinds of discourses the participants draw on and the kind of subject positions they adopt when constructing their identities as language learners and users.

\section{On identity and the use of English as a lingua franca}

\section{Earlier studies on identity and language learning}

What is true of identity research in general also applies to research on identity and language learning; recent studies adopt a social constructionist or poststructuralist approach, acknowledging the fluid nature of identity and the existence of multiple identity options also for language learners (see for instance Norton and Toohey 2002: 116). An important earlier study is that of Norton (2000), who concentrated on second language learners' identity construction in contexts where the language is spoken as a native tongue. In particular, she investigated immigrants in Canada, their language learning histories and identities and the relationship between identity, language learning and social context (home, workplace and school). Drawing on Bourdieu's (1991) concept of legitimacy, Norton uses the term ownership and argues that foreign language learners either can or cannot claim ownership of the language they learn; if they cannot, they do not feel like legitimate speakers of the language. While the concept of legitimacy is often used in connection with speakers who strive to learn the language of the surrounding society, it is also an important notion in lingua franca contexts as this paper aims to demonstrate.

Most studies on identity and language learning have been qualitative and the data have comprised diaries (Norton 2000), narratives (Polanyi 1995), autobiographies (Pavlenko 2003) interviews and questionnaires (Pomerantz 2001). Ethnographic approaches (McKay and Wong 1996, Lam 2000) have also been used, and multilinguals and their language choices have been studied in relation to issues of power (Pavlenko and Blackledge 2004). As regards specific contexts of study, McKay and Wong's (1996) longitudinal ethnographic study investigated four adolescent Chinese immigrants in a Californian high school and - of particular significance for the present study - their positions in different discourses; Murphey et al. (2004) studied Japanese and Taiwanese ESL students' language learning histories and their constructed identities and imagined communities. Pomerantz (2001) investigated foreign language learners' identities by studying the discursive construction of their Spanish learner identities in classroom contexts, whereas Kanno's (2003) focus was on how bilingual individuals position 
themselves between two languages and two (or more) cultures, and how they incorporate these languages and cultures into their sense of themselves.

What these earlier studies suggest is that learners negotiate different identities in different contexts (such as educational and non-educational) and are situated in a number of discourses, often because of their different histories as learners of English, their backgrounds, and discourses of power (e.g. McKay and Wong 1996: 595). For instance, Lam (2000), when investigating an immigrant Chinese teenager's writings on the Internet over a period of six months, found that in the classroom context the learner could only negotiate negative identities because his use of English was considered 'against the rules' of education, i.e. grammatically incorrect. However, outside the classroom, on the Internet, the learner was engaged in new discourses, such as pop culture and religion, in which he was able to construct alternative identities which made him feel more proficient. As a further example on the relationship between identity and foreign language, Pavlenko (2003) analysed pre- and in-service English as a second language and English as a foreign language teachers' linguistic autobiographies; her findings suggest that the traditional discourse of linguistic competence positions teachers as members of either native speaker or non-native speaker/L2 learner communities. These earlier studies form an important reflective background for this study as they have explored language learners' identity work both in educational and everyday contexts and shown it to vary across contexts. Adopting a longitudinal approach, the present study aims to contribute to this discussion by investigating how Finnish engineering students' discursive identity construction is linked to educational and everyday lingua franca contexts and their discourses, i.e. how their identity options change over time and across contexts.

In earlier studies of periods spent abroad, the focus has been on the development of foreign language skills rather than on identity construction (e.g. Freed ed. 1995, Pellegrino 1998). These studies are often longitudinal, focusing on the kind of changes that language learners undergo during their stay abroad (see for instance Polanyi 1995). There are fewer studies of students' actual experiences in the context of their stay abroad. However, Jackson (2008) studied English majors in Hong Kong before and after their sojourn and found that the overseas period affected their confidence and appreciation of English. Kinginger's (2004) study, on the other hand, shows how a period abroad may also lead to feelings of anger and frustration (see also Kinginger and Belz 2005 for effects of stay abroad). These studies suggest that spending time in countries where the target language is spoken as the main language can have powerful effects on language learners' self-perception; this study explores the extent to which this also applies to lingua franca contexts.

\section{Identity issues in lingua franca research}

In foreign/second language education, the underlying assumption usually is that native speakers provide the model towards which learners are striving. As native speaker competence is a target difficult to achieve, learners are practically for ever just that, learners. The learner perspective has been prevalent in mainstream SLA research, a stance heavily criticized by Firth and Wagner (1997) when they argue that SLA research pays too much attention to learners' errors and deficiencies and too little to language learners as 
language users and as social actors with interactional accomplishments. In lingua franca research, it is the very notion of treating people as language users that according to its proponents distinguishes it from approaches that focus on people as 'mere' language learners (e.g. Jenkins 2007; Seidlhofer 2001).

English as a lingua franca (ELF) research is a relatively recent and controversial area of research (Jenkins 2007). Although there are variations in how ELF is defined, there seems to be consensus that English as a lingua franca is a contact language used among people who do not share a common native language, and it is commonly understood to mean a second (or subsequent) language of its speakers (Jenkins 2007: 1; Firth 1996: 240). In recent years there has been rapid growth in ELF research (see for instance Mauranen et al. 2006; Seidlhofer 2001, 2004; Jenkins 2000, 2007; Pölzl 2003; Cogo and Dewey 2006). Although identity is touched upon in these studies, it has not been researched extensively (but see Jenkins 2007). This is perhaps because ELF has been perceived as serving very practical purposes of information transfer rather than featuring strongly in identity construction. For example, House (2003) argues that lingua franca language is for communication rather than for identification. Similarly Dörnyei's (2006:9 as cited in Jenkins 2007:198) remark that many L2 English learners and users may in the future no longer wish to integrate into an NS English culture, but into what he refers to as 'the world at large' suggests that matters of identity may be less significant in ELF contexts than in situations where learners wish to integrate into specific cultures.

However, questions of identity are also worth studying in ELF contexts, not least because they usually involve people from different linguistic and cultural backgrounds, which may well bring issues of identity to the surface. Jenkins (2007: 43), for example, talks about ELF interaction allowing speakers' native-culture identities to 'shine through' (cf. Seidlhofer 2006: 43). Pölzl (2003: 4-5) takes a different stand on this, arguing that English in lingua franca contact situations is used as a native-culture-free code. This means that ELF users have the freedom to either create their own shared, temporary culture, to partly 'export' their own individual primary culture into ELF, or to reinvent their cultural identities by blending into other lingua-cultural groups. As any people's identities, also ELF speakers' identities are thus never static but are constructed within interaction (e.g. Cummins 1996) and can involve membership in various groups, such as the ELF group or their primary culture group (Pölzl 2003: 7).

When discussing issues of identity in relation to English as a lingua franca, Jenkins (2007) proposes a perspective on foreign language use that differs from the traditional SLA view, in which differences from NS English norms are automatically regarded as deficiencies. She (2007: 202) refers to Omoniyi's (2006) identity hierarchies model, which opens up the possibility of approaching differences from native speaker norms as identity-driven, with speakers being aware of what a native speaker of English would do at a given point but deliberately choosing to do something else, perhaps in order to signal a shared identity with a particular NNS interlocutor. The recognition that disregarding native speaker norms may signal a more desired identity is crucial for the investigation of identities of users of English as a lingua franca.

The points raised above about identity repertoires varying across contexts are important for this paper, which aims to shed new light on identity construction in lingua franca contexts. Further, by exploring Finns' perceptions of their use of English in ELF 
contexts both before and after their six-month stay in Germany, the study offers a longitudinal perspective on identity construction. A longitudinal perspective is useful in revealing how identities are constructed at different times, on different levels and in different contexts by the same people, i.e. how identities change in processes of transition.

\section{Data and methods of analysis}

The data comprise of interviews with seven Finnish engineering students (aged 21-26) who were enrolled in a polytechnic and carried out an internship of 4 to 6 months in Germany in 2003. They were interviewed both at the beginning of their stay and after it. The researcher accompanied the participants to Germany, but participant observation was not part of the study. The purpose of the interviews was to explore the effects of the period abroad on participants' conceptions of themselves as users of foreign languages, especially English. The first interviews concentrated on themes such as foreign language proficiency in general and the participants' views of their own language proficiency in particular. Also their feelings as users of English and of staying abroad were explored. In the second interviews, the same themes were investigated, with the emphasis on their actual experiences of being abroad and the effects it had on them as foreign language users.

The participants' educational backgrounds were similar: they had all studied English for seven years at junior and secondary school and for three years in either high school $(n=4)$ or vocational school $(n=3)$. Altogether, they had learned English as a subject for ten years at school, and also during a few of their courses at polytechnic. Prior to their internship no one had travelled abroad for more than two weeks and no one reported having used English in Finland apart from at school. That is, their experience of using English was almost entirely related to their education.

The interviews were analyzed using discourse analytic methods (e.g. Fairclough 2001, 2003; Gee 2005) which paid attention to both content and form. Firstly, recurring themes and topics were identified and, secondly, attention was paid to the language choices participants made to talk about these topics. In concrete terms, language analysis involved concentrating on the words and structures participants used to express particular themes, discourses and subject positions. This analysis provided material which, in turn, can be interpreted in terms of identity work. Rampton (2007:2) rightly points out that even though language and discourse are the major sites for research, identity cannot be accessed directly by empirical analysis but tends to feature as "second- or third-order abstraction". Also in this paper, arguments about identity are based on analyzing and making sense of what the participants say about their use and learning of English, the ways in which they formulate their opinions, and how they position themselves in relation to English.

\section{Findings}

\section{Before the stay abroad: discursive constructions of learner identity}

As pointed out above, the first interviews, before the stay abroad, explored the participants' understanding of language proficiency in general and of their own foreign language skills in particular. What all participants shared in these interviews was a strong orientation to 
language education in school, i.e. their most readily available identity option was that of a language learner. Although this is hardly surprising, given that their experiences of foreign languages mainly derived from educational contexts, it is of interest to explore which themes and topics they draw upon more specifically in this identity work. In the following, the first interviews are discussed in the light of recurrent themes that emerge throughout the interviews: the participants experiencing their skills in English as inadequate, their references to the compartmentalized nature of language, and their lack of access to English outside school.

\section{Self-evaluations of language proficiency: Voicing educational discourses}

A noticeable feature in the first interviews is that all the participants describe themselves as having rather poor skills in English. Their discursive constructs are often quite straightforward in answer to the question about their language skills, as the following examples show:

$$
\begin{array}{ll}
\begin{array}{l}
\text { Tiina } \\
\text { Pete } \\
\text { Tiina } \\
\text { Pete }
\end{array} & \begin{array}{l}
\text { do you think you are good at English } \\
\text { no not at all } \\
\text { why do you say that } \\
\text { I've never been a star at school }
\end{array} \\
\text { Joel } & \text { they [skills in English] are not particularly good }{ }^{2} \\
\text { Oskari } & \begin{array}{l}
\text { I wouldn't say they're good because speaking is [---] totally about searching } \\
\text { for words }
\end{array} \\
\text { Tiina } & \begin{array}{l}
\text { so you think you are a bit better [than the Germans] } \\
\text { Simo it seems although I don't consider myself a very good speaker } \\
\text { as I haven't done that well at school }
\end{array}
\end{array}
$$

Examples (1) and (4) demonstrate how school is explicitly mentioned as the context within which Pete and Simo evaluate their skills. That is, school is given as an explanation for their evaluative statements (e.g. in extract 1 Pete is asked to explain his negative answer, and in extract 4 , school is mentioned to justify the negative evaluation). However, Joel and Oskari (examples 2 and 3) refer to their poor skills in more general terms. Although the interviewer's question introduces the notion of 'good skills' in the first place, the way the point is developed about not having particularly good skills is the participants' own choice and clearly echoes discourses of education, where there is a strong tendency to evaluate different aspects of students' foreign language performance. The following extracts serve as examples of the numerous instances in which the participants assess their language proficiency as not good enough:

\footnotetext{
1 Interview extracts are translated from Finnish into English. Bracketed full stops indicate pauses, text within square brackets contains relevant contextual information, three lines in square brackets indicate that some interview material has been omitted for clarity. Pseudonyms are used for reasons of confidentiality.

2 Joel and Oskari answer to the same question as Pete
} 
Tiina how would you compare your skills in relation to other Finns

Simo [--- $\quad$ my grammar isn't strong at all

Tiina what [language skills] would you hope to have

Lauri vocabulary could always be better

There is an evident emphasis on a lack of skills throughout the interview data. In extract (5) Simo explicitly assesses his skills in relation to other Finns as asked to, but quite often the yardstick by which the interviewees measure their language skills remains implicit when they assess them as not very good (as when Lauri in example 6 maintains that his vocabulary 'could be better'). The point of comparison might be their peers' skills or the demands presented in language education, or both. However, the idea of having to reach certain standards to be deemed 'good' is evident throughout, and can be seen as a reflection of the evaluative discourses of schooling. When paying attention to word choices, all the participants in extracts 1-6 echo the word choice good introduced by the interviewer, or use other evaluative words such as strong and better, often with negative statements (e.g. not good and not strong).

\section{Compartmentalized language skills and native speaker norms}

Another related feature which contributes to the construction of learner identity and draws upon discourses of education is the way participants choose to discuss their skills in relation to specific areas of language such as vocabulary, grammar and tenses, a tendency already evident in the extracts above. This compartmentalized view of language probably derives from discourses of education, which tend to itemize language into its constituent parts. Again, participants choose to focus on aspects they are not good at, i.e. making a contrast between the kind of language they use and what they deem to be correct or proper use of language (which is probably that used by native speakers, as suggested by Simo's reference to native speakers in extract 9)

$$
\begin{array}{ll}
\begin{array}{l}
\text { Tiina } \\
\text { Tero }
\end{array} & \begin{array}{l}
\text { do you think you have good language proficiency in English } \\
\text { well it's good enough but could be better [---] } \\
\text { maybe my vocabulary could be a bit larger than it is now }
\end{array} \\
\begin{array}{ll}
\text { Tiina } & \text { what was it more specifically [where your learning got stuck at school] } \\
\text { Pete } & \text { well it's this grammar stuff } \\
& \text { how good are you at speaking English } \\
\text { Tiina } & \text { [---] pronunciation is probably not that (.) it is not nice to hear (.) } \\
\text { Simo } & \text { if English people listen to it }
\end{array}
\end{array}
$$

In extract 7 Tero first describes his skills as good enough but then introduces a contrastive element with the word but, followed by his reference to vocabulary as the area of language in which he needs to improve. Pete (extract 8) describes his skills in relation to grammar, whereas Simo (extract 9) focuses on speaking, saying that it is not nice to hear, mentioning native speakers as potential evaluators of his speaking. Education and schooling, and particularly adherence to native speaker norms, thus seem to be the main discursive 
resources upon which the participants draw when describing their relationship to English before their stay abroad. Although the interviewer's influence in triggering evaluative speech is great, it is nevertheless interesting that the participants almost invariably attach themselves to subject positions which are characterized by insufficiency and inadequacy. This is in significant contrast to what participants said when describing language proficiency in more general terms (see their answers to 'How would you define good language proficiency' in examples 10-12 below). These responses bring in alternative voices from within discourses of education that emphasize communication and coping. These more positively-oriented discourses are hence also available but are simply not drawn on when participants describe their own language proficiency, which suggests a divide between what they conceive of as an ideal situation and their own everyday experiences:

$$
\begin{aligned}
& \text { Tero } \quad \text { well you cope with it in everyday life [---] it is quite sufficient } \\
& \text { Oskari that one survives with practical matters of life in a foreign language } \\
& \text { Simo }
\end{aligned}
$$

\section{Locating English 'outside' everyday life}

Besides the participants' choosing to bring to the fore their 'not-so-good' skills in English in general and their inadequate mastery of specific areas of language, a further common theme emerging in the first interviews is the tendency to construct English as something outside everyday life. When asked how and whether they use English in Finland, almost all of them answered little, very little or not at all, as shown in examples 13-15 below. Interestingly, Simo's reference to not having access to speaking in real situations implies that he does not consider school to be a real context of language use:

$$
\begin{aligned}
& \text { Tero very little (.) speaking is very rare } \\
& \text { Joel not at all except that you throw in some words in English as all Finns do [---] } \\
& \text { because there is no one to talk to [in English] } \\
& \text { Tiina how did you feel about living in Germany } \\
& \text { Simo well (.) before leaving I was (.) a bit frightened at first (.) whether I'll get } \\
& \text { along [---] since I've never like really had access to speaking in real } \\
& \text { situations }
\end{aligned}
$$

Although English has a strong presence in today's Finland and especially in the lives of the young, many of whom are in constant contact with English through various forms of the new media and information technologies and through products of popular culture (see Leppänen \& Nikula 2007), the interviewees do not seem to regard such contacts as really using English (cf. Lauri's comment well of course I always surf on the Internet on sites that are in English but I don't mail with anyone so that I need to use English). It seems, then, that speaking is seen as the use of a foreign language (cf. extracts 
13-15). The fact that opportunities to speak English are rare may explain why most of the participants describe situations in which they have to use English as emotionally demanding: words either directly or by implication referring to negative feelings occur quite frequently in the first interviews:

$$
\begin{array}{ll}
\text { Tiina } & \text { so how would you describe your speaking } \\
\text { Oskari } & \text { [---] I kind of don't give myself enough time to think about the words and } \\
\text { there's kind of (.) pressure to talk (.) and } \\
\text { the easiest words come out which we have had from the start } \\
\text { Lauri } \\
\text { [as an explanation for not having good language skills] } \\
\text { well I maybe sometimes unnecessarily (.) I think too much about it (.) } \\
\text { how to say it and (.) and how to get the words right } \\
\text { Simo } \\
\text { well I hoped before leaving that speaking English (.) would become more } \\
\text { natural (.) if someone came and spoke English I would be able to speak back } \\
\text { right away (.) so that I wouldn't have to think and get embarrassed like oh } \\
\text { hell no (.) that guy's started speaking English what should I do }
\end{array}
$$

In extracts 16 and 17 constructions such as pressure to talk and I think too much relate to both poor language skills and discourses of language learning. Simo's discursive choices in relation to speaking English point towards strong negative feelings, as he uses a swear word (hell no) to mark his position as an insecure language user. Although the discursive choices in the first interviews largely contribute to the creation of a (poor) language learner identity, the interviews also show some evidence of the participants subscribing to identities such as those of a 'survivor' or one who manages to cope with his English in everyday life: a language user identity is thus also evoked. This does not mean that there is a clear division between participants who position themselves as language learners and those who see themselves as language users. Rather, there are moments when discourses of language education and learner identity associated with them are accompanied by other identity options, as in the following extracts (19 and 20), where Pete and Lauri within the same utterance activate both language learner identities (I've never been a star, I don't have a good head for languages) and survivor identities (I know enough to get what I need, I will survive).

$$
\begin{aligned}
& \text { Pete } \begin{array}{l}
\text { I don't know it [English] very well I've never been a star } \\
\text { but in reality I know enough to get what I need and I won't starve }
\end{array} \\
& \text { although I don't have a good head for languages (.) there are some things I } \\
& \text { always have (.) I can always use my hands and legs so (.) I will survive }
\end{aligned}
$$

In example 19 Pete first positions himself as a poor language learner (I've never been a star) and then makes a contrasting move towards a position of language user marked by the word choice but and the following description of himself as someone who manages to get what I need. A similar strategy is used by Lauri, who draws upon contrasting discourses by first saying that he does not have a good head for languages and then referring to his ability to survive. Also extract (21) serves as an example of competing 
discourses: the way Simo talks about pronunciation has the double function of both playing down his skills and signalling affinity with other Finns with the same shortcoming. Thus discourses of education are powerfully present when the basic Finnish way of speaking becomes defined as undesirable. On the other hand, Simo also seems to resist that power by aligning himself with those Finns for whom native-like language use carries overtones of acting in a fancy way, i.e. not being true to oneself.

Simo

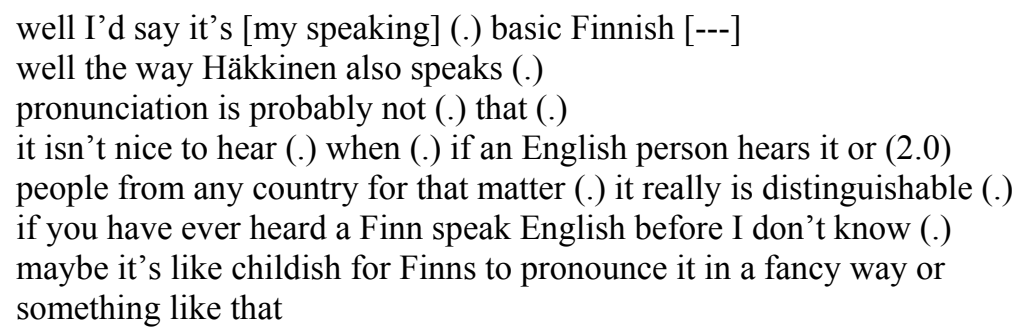

Findings from the first interviews demonstrate the complex nature of these engineering students' relationship to a foreign language that they have learned for ten years at school: it evokes a mixture of descriptions, experiences and feelings. Clearly the contexts of Finland and schooling as well as a lack of experience in using English have a significant impact on the discursive positions adopted. Although the participants have a pragmatic view of English as a language for communication in general, their own positions tend towards that of incompetent users of English who need to learn specific items of the language. Adopting subject positions as unsuccessful learners implicitly signals the power assigned to native speakers as the norm to which they compare their performance: relation to this norm is seen not only in terms of difference but also in terms of deficiency (cf. Jenkins 2007).

\section{After the stay abroad: discourses of deficiency giving way to discourses of proficiency}

During their 4-6 months in Germany, the participants lived in a students' hall of residence with people from various cultural backgrounds (German, Indian, Chinese, Greek etc.) and had daily contact with them, as well as with other Germans whom they worked with or otherwise encountered during their stay. In those encounters English was the principal language used, except for work, where they were advised to use only German. After their stay the participants were interviewed again. As in the first interviews, the second interviews concentrated on language proficiency and the participants' views of themselves as users of English in addition to their experiences of using English in Germany. How they saw the effects of the stay abroad on their language skills was also one of the themes.

In many respects, the participants' way of constructing their relationship to English is different in the second interviews. For example, they embark on positioning themselves discursively as users of English rather than as incompetent learners. Their discursive choices also shift from concerns about coping with discrete language skills such as grammar, vocabulary and speaking to descriptions of survival in English and using it in daily life. The second interviews will be discussed here in the light of three recurring 
themes that arose in them: the sense of survival and coping in a foreign language, a diminishing concern for correctness, and the emergence of groups of other lingua franca speakers rather than native speakers as the point of comparison for Finns' skills in English.

\section{Identity shifts: from learners to users}

As pointed out above, in the first interviews the engineering students perceived themselves as not very good users of English and they regarded their skills as inadequate in many respects. This rather negative self-image is no longer common in the interviews after their stay abroad. Instead, the participants more often draw on discourses of coping, positioning themselves as language users who manage to get by. This is illustrated by the following examples, where the interviewees explicitly compare how things 'now', i.e. after their stay, differ from the way things were earlier. References to obstacles and difficulties diminishing and courage to use English are discursive choices that did not occur before they went abroad:

$$
\begin{aligned}
& \text { Pete } \\
& \text { nowing it [a presentation in English] is like a completely different obstacle } \\
& \text { Oskari } \quad \text { there surely was an obstacle at the beginning [in speaking] } \\
& \text { but it has been getting easier all the time and surely will continue to do so } \\
& \text { nero } \\
& \text { now I dare to use English maybe more than at the beginning (.) } \\
& \text { I guess I now take part more actively in conversations }
\end{aligned}
$$

These examples clearly point towards a change, strengthened by the references to time. Pete for instance says that now the obstacle he faces when making a presentation in English is totally different, and Oskari and Tero refer to the existence of an obstacle at the beginning (i.e. before the stay), in contrast to the situation now, i.e. after the stay, when the problems have begun to disappear and one is a more active user of English.

\section{Celebrating successful language use}

Another common feature across the second interviews is reference to the positive feelings brought about by experiences of success as a foreign language user. Successful experiences are often framed as surprising which, by implication, suggests that the position of a poor foreign language user had more or less been taken for granted, i.e. assumed (Pavlenko and Blackledge 2004). The following extracts illustrate well how the emergence of new identity options can be an empowering experience. For example, Simo's winner metaphor in extract (26) is in clear contrast to the way he described himself as an unsuccessful leaner in the first interviews and suggests that the period abroad has made him see himself as a legitimate user of English (cf. Norton 2000)

$$
\begin{aligned}
& \text { Oskari at first I suspected that there might be inadequacies [in my skills] } \\
& \text { that I wouldn't cope very well } \\
& \text { but I have coped surprisingly well }
\end{aligned}
$$


and I sort of gained in self-confidence a bit

$$
\begin{array}{ll}
\text { Simo } & \text { well yes it [getting along in Germany] was a really big surprise to me } \\
\text { Tiina } & \text { right (.) so how did it make you feel then } \\
\text { Simo } & \text { well you know it sort of made me feel like a winner } \\
\text { Tiina } & \text { so how did it make you feel when you were able to say what you really } \\
& \text { wanted } \\
\text { Tero } & \begin{array}{l}
\text { well yes it felt quite good } \\
\text { and there was a sort of a feeling of success }
\end{array}
\end{array}
$$

Like Simo, Tero (27) too positions himself as a successful user of English. Oskari in extract (25) also refers to a change as he first discursively adopts a position as an incompetent user of English with deficiencies in certain skills, but then immediately with the word but makes a move to a position as a confident survivor, accompanied by the word choice surprisingly, which suggests an identity option available for him for the first time.

\section{Language as meaning over form}

That identity as a foreign language learner starts to get replaced by, or at least accompanied by, identity as a language user also shows in another noticeable difference to the first interviews: participants no longer put as much emphasis on correctness and mastery of specific areas of language. They still talk about issues such as shortcomings in grammar and vocabulary, i.e. drawing on discourses of language education, but counterbalance these with references to coping and to how questions of form do not constitute a barrier to successful communication, i.e. speaking from within discourses that emphasize meaningful language use. In essence, discursive choices that in the first interviews were made only when talking about general views of language proficiency (see examples 10-12) are now also drawn on when the participants describe themselves. As the examples below show, Oskari and Tero draw on two different discourses: one of mastery of language skills and words (i.e. getting it exactly as it should be and vocabulary could be larger) and the other in which correctness, feelings of annoyance, and doubt about getting along have been superseded by coping.

$$
\begin{aligned}
& \text { Oskari so so (.) it doesn't sort of anymore (.) make me feel annoyed } \\
& \text { if it doesn't come out exactly as it should be } \\
& \text { Tero well yes maybe of course the fact that you noticed how your vocabulary } \\
& \text { could be larger but anyway at the end I could say that now now I've courage } \\
& \text { to go anywhere in the world (.) perhaps I no longer think that I'm so bad at } \\
& \text { English that I wouldn't be able even to cope in it (.) now I've noticed that I } \\
& \text { can get along }
\end{aligned}
$$

We vs. them: other groups of ELF users as the new point of comparison 
Apart from their stay abroad clearly affecting participants' discursive positions and making them subscribe to subject positions not only as learners of English but also as its users, there are also other differences between the first and second interviews. Something that arises in most interviews is that the participants begin to talk from within a broader perspective: not only as individual users of English whose performance is compared to that of native speakers, but from a collective perspective as Finns in comparison to other users of English. This is illustrated in extracts 30-31, where the participants position Finns collectively in favourable terms when compared to Germans and others who use English as a foreign language. In this collective ELF identity work, the focus is on speaking competence (although there are some references to vocabulary and accent too).

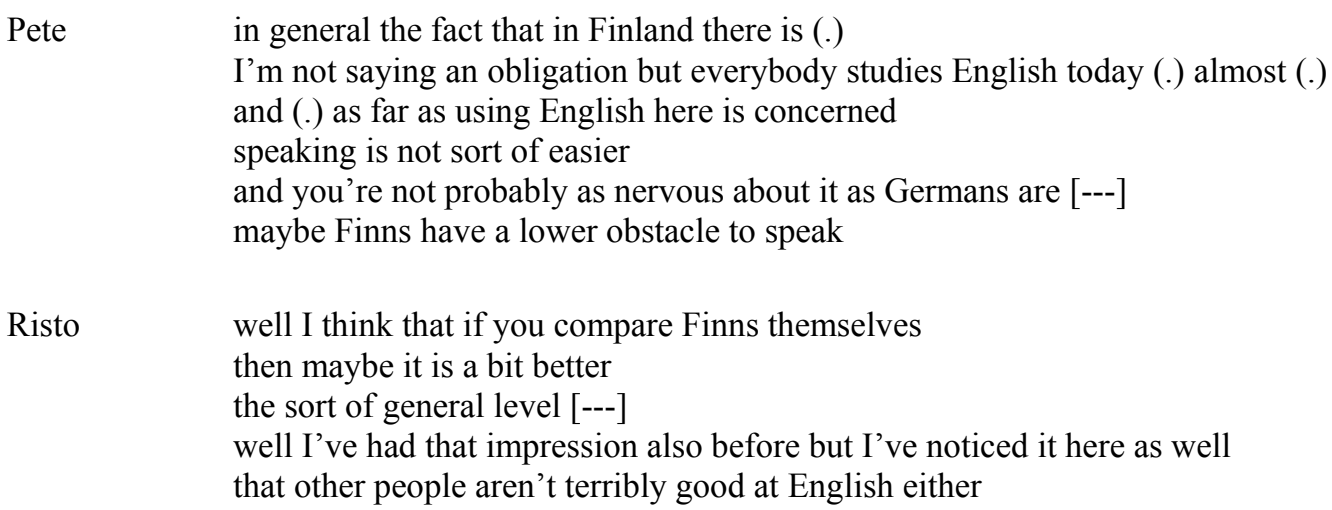

In extract (30) Pete is asked to discuss what features of his own English skills on the one hand helped him get along in Germany and on the other hand prevented him from doing so. But instead of answering from his personal point of view, he chooses to talk about language proficiency in Finland and Finns' skills in general. Perhaps comparing oneself to others is safer collectively, especially when seeing one's own group in a more favourable light, as Pete does here when comparing Finns with Germans. The same feature is seen in extract (31), where Risto views Finns' skills as a bit better than those of other Europeans and also concedes that other people are not terribly good at English either. These all point towards localization of English as participants share a sense of nationality and communality.

Contrasting us and them can, obviously, lead to national stereotyping, but in this case adopting a collective identity as 'we Finns' and relating this to other groups also serves as a way of putting into perspective participants' earlier concerns about speaking English fluently, as also other people share similar shortcomings. This is also seen in the following extracts, where Simo and Joel compare their own foreign language skills with others, coming to the conclusion that their skills are, in fact, better. Such discursive positionings were absent from the first interviews, where references to one's own poor skills dominated.

Simo

if I can say that I have had some sort of advantage over others (.) sort of when speaking English (.)

so I probably know at least in my own opinion I know more than 
people I have spoken with here

$$
\text { Joel }
$$

well heh maybe it feels somehow as if I'm able to speak a bit clearer myself myself as the way Indians speak is so inarticulate kind of (.) so in that sense I maybe know sort of (.) better better

As quite often elsewhere, Simo in example (32) draws on discourses of language proficiency. However, compared to the situation before going abroad, which was characterized by fear and the lack of opportunity to speak in real situations (see example 15 ), this other discourse offers him new identity options, such as those of a winner and a more skilful language user (I know more) than his interlocutors. It remains implicit who these interlocutors are, whereas in example (33) they are explicitly referred to as Indians by Joel, which is interesting considering the fact that English is an official language in India. Like Simo earlier, Joel too positions himself as better than others at speaking English.

What emerges from the second interviews is important in its own right but it gains even more significance when set against the findings of the first interviews. Feelings of fear have given way to feelings of success, and worries about correctness have been replaced by references to coping and communicative skills. Furthermore, emerging features resulting from the opportunity to use English as a lingua franca are that of a collective language user identity and the emergence of new norm for comparison: other non-native speakers or users of English in lingua franca contexts. A discursive position as a language user in the community of ELF users is a new resource for identity-building available to the participants. A shift from adherence to native speaker norms to those of lingua franca users, a novel discourse, can thus be identified.

\section{Transitions in contexts, discourses and identities}

A longitudinal approach makes it possible to trace different transitions, the changes that people undergo over a period of time: in this study transitions that Finnish engineers experienced during a few months spent abroad. Transition took place in various ways: at the level of contexts, as the participants moved from educational contexts to those of a stay abroad; in terms of discourses, as they drew upon different discourses from those used in the first interview than in the second interview; and in their identities. More specifically, they moved from a Finnish context in which English was seen from within an educational space to a foreign context in which English was a resource for everyday lingua franca communication. The changing contexts had an impact on the discourses participants drew upon in their talk. Thus access to new social and linguistic resources abroad resulted in the adoption of new identity repertoires which included features such as fewer psychological barriers to using English, increasing courage as speakers, and feelings of survival and success, while the educational discourses with their language learner positions started to lose their power. At the same time, discourses of deficiency gave way to discourses of proficiency.

Significantly, the sense of growing proficiency and confidence was related to using English with other non-native speakers, which suggests that lingua franca contexts may be conducive to developing self-awareness as a foreign language user in ways 
different from encounters with native speakers, and particularly different from experiences in school contexts. This growing confidence can be captured by the notion of legitimacy, which the participants adopted as users of English as a lingua franca by positioning themselves as free from certain native speaker norms, such as having perfect pronunciation or 'getting things exactly right'. Such sentiments were absent in the pre-stay interviews, where there was frequent reference to using English with close adherence to rules and norms. More specifically, the participants identified themselves as legitimate users and speakers of lingua franca English by describing how they survived in lingua franca situations, were successful, and had freedom of choice on how to speak and how to feel when speaking. This is in line with Bourdieu's (1991) and Norton's (2000) discussions of legitimacy and ownership.

According to Pavlenko and Blackledge (2004), some identities are assumed, some are imposed upon us, while others are negotiable. In the present study, identities related to learning had been assumed by or even imposed upon the participants, whereas in the context of being abroad the identities linked to using English as a lingua franca were more negotiable. As Blommaert (2005) argues, identity repertoires are conditioned by forms of access to particular identity-building repertoires. Through transitions new identity-building repertoires became available and new identities negotiable (see also Thesen 1997). Issues arising before the stay abroad were related to competence and language skills and identity construction focused on the individual level. After their experiences with speaking and using English abroad the participants reported having Finnish features in ways that suggested acceptance of these features and reluctance to fully identify with native speaker models, which can be interpreted as an indication of lingua franca user identities that are distanced from the native speaker norm.

The transition in identification from learner to user identity can also be approached from the perspective of power, which in each situation involves either enabling or constraining the range of identities available for negotiation (Cummins 1996:15). In educational discourses, native speaker norms have power, but power relations appear to be different in contexts abroad, where participants can negotiate identities as lingua franca users. However, besides providing more powerful identity options, lingua franca contexts also provide opportunities for shifting power relationships and new identity options. As Jenkins (2007:201) argues, "there is a second tier of power relations in ELF interactions, i.e. among ELF speakers themselves, to the extent that they see ELF varieties not as equals but as hierarchical" (emphasis added). This shows in the present study in the way that some participants feel more powerful in relation to other lingua franca speakers of English, such as Germans. Given the findings discussed in this article, power is a major influence in how users of ELF both position themselves (as individually and/or collectively) and ascribe identities to each other (see also Jenkins ibid.).

\section{Conclusion and implications}

Staying abroad can be expected to shape foreign language users' perceptions, and this assumption is confirmed by this study. More specifically, it highlights the discursive nature of such changes: the relatively short stay may not have changed much in terms of the Finnish engineering students' actual language proficiency, but its effect on the way they 
discursively construct themselves in relation to English is remarkable. This sheds some light on "the process by which individuals construct new identities for themselves" (Benson 2005:19) when encountering new social situations as foreign language users. The study also confirms that rather than being a single entity, identity is in constant flux, which shows in the participants simultaneously positioning themselves in different discourses. The rich set of multiple, layered and at times contesting identities constructed included those of language learner, language user, legitimate user of English as a lingua franca as well as Finnish user of English. The study thus suggests that there is indeed a relationship between identity and ELF and that this relationship is complex. Cameron (2001: 91) illustrates the importance of identity work in learning by saying that questions like "who am I when I speak this language" are crucial in the process: this was also reflected in this study, where the second interviews in particular brought out issues of legitimacy when the participants negotiated their right to use English in ways clearly distinguishable from native speakers and their preference for doing so.

The results show how education plays a key role in the production and reproduction of identities and relations of power (cf. Bourdieu and Passeron 1990). The participants were found to draw both explicitly and implicitly on discourses of education, especially but not only before their stay abroad. They did so in ways that tended to highlight inadequacies and shortcomings, i.e. the learner identity that emerged was rather negative. On the other hand, the participants' experiences during their stay abroad quite quickly gave rise to more favourable perceptions of themselves as foreign language users that manage to get by despite shortcomings in proficiency. Moreover, divergence from native speaker norms was often seen as an assertion of one's identity rather than a problem. As regards the implications for foreign language education, it would seem important that education should open up the possibility of learners adopting more favourable identities so that instead of seeing themselves as failed native speakers they began to see themselves as multicompetent speakers (Cook 1999: 204). Although teaching for communicative competence and learning languages in order to use them have, of course, been at the heart of language teaching for decades, the present findings show how deeply ingrained issues of deficiency are in discourses of education and how much remains to be done before school is a place where learners can assert their identities as competent speakers "not with a borrowed identity but with an identity of their own as international users of an international language (Seidlhofer 2003: 23)."

Drawing wide-ranging conclusions on the basis of interviewing seven participants is, of course, difficult and we recognize the need for much more research on lingua franca identities. For example, it would be useful to carry out research that would complement interviews both with instances of language use in lingua franca contexts and with language users' own conceptions and understandings of these contexts. However, despite its limited scope, we hope that this study has managed to provide insights into the complex ways in which lingua franca language use, as well as being a matter of communication, is to a great extent also a matter of identification.

Acknowledgements 
Financial support by the Academy of Finland is gratefully acknowledged. We also wish to thank the two anonymous reviewers for their constructive and insightful comments and M.A. Eleanor Underwood for proofreading the manuscript.

\section{Bibliography}

Block, D. 2007. Second language identities. London: Continuum.

Block, D. 2006. Multilingual identities in a global city: London stories. London: Palgrave.

Benson, P. 2005. (Auto)biography and learner diversity. In Benson, P and D. Nunan (eds.), Learners' Stories. Difference and Diversity in Language Learning. Cambridge: Cambridge University Press. 4-21

Blommaert, J. 2005. Discourse: a critical introduction. Cambridge: Cambridge University Press.

Bourdieu, P. 1991. Language and symbolic power. Edited and Introduced by J.B. Thompson. Translated by G. Raymond and M. Adamson. Cambridge: Polity Press.

Bourdieu, P. and J-C. Passeron 1990 (1977). Reproduction in education, society, and culture. London: Sage.

Cameron, D. 2001. Difficult subjects. Critical Quarterly, 42(4), 89-94.

Cogo, A. and M. Dewey. 2006. 'Efficiency in ELF Communication: From pragmatic motives to lexico-grammatical innovation'. Nordic Journal of English Studies 5(2), 59-94. http://hdl.handle.net/2077/3148

Cook, V. 1999. Going beyond the native speaker in language teaching. TESOL Quarterly, 33 (2), 185-209.

Cummins, J. 1996. Negotiating identities: education for empowerment in a diverse society. Los Angeles: California Association for Bilingual Education.

Davies, B. and R. Harré 1990. Positioning: the discursive production of selves [online]. (accessed 24 July 2006) http://www.massey.ac.nz/ alock/position/position.htm

Fairclough, N. 2001. The Discourse of new labour: critical discourse analysis. In M. Wetherell, S. Taylor and S. J. Yates (eds.), Discourse as data. A guide for analysis. London: Sage, 229-266.

Fairclough, N. 2003. Analysing discourse: textual analysis for social research. London: Routledge. 
Firth, A. 1996. 'The discursive accomplishment of normality. On "lingua franca" English and conversation analysis'. Journal of Pragmatics 26: 237-59.

Firth, A. and J. Wagner. 1997. On discourse, communication and (some) fundamental concepts in SLA research. Modern Language Journal, 81, 285-300.

Freed, B. (ed.) 1995. Second language acquisition in a study abroad context. Amsterdam: John Benjamins Publishing Company.

Gee, J.P. 2005. An introduction to discourse analysis. New York: Routledge.

Gergen, K. J. 1999. An invitation to social construction. London: Sage.

Hall, S. 1996. Introduction: who needs 'identity'? In S. Hall and P. du Gay (eds.), Questions of cultural Identity. London: Sage, 3-17.

House, J. 2003. English as a lingua franca: a threat to multilingualism? Journal of Sociolinguistics 7 (4), 556-578.

Ivanić, R. 1998. Writing and identity. The discoursal construction of identity in academic writing. Amsterdam: John Benjamins Publishing Company.

Jackson, J. 2008. Language, Identity and Study Abroad: Sociocultural Perspectives. British Studies in Applied Linguistics: Equinox Publishing Ltd.

Jenkins, J. 2000. The Phonology of English as an International Language. Oxford: Oxford University Press.

Jenkins, J. 2007. English as a lingua franca: Attitude and Identity. Oxford: Oxford University Press.

Kanno, Y. 2003. Negotiating bilingual and bicultural identities. Japanese returnees betwixt two worlds. Mahwah: Lawrence Erlbaum Associates.

Kinginger, C. 2004. Alice doesn't live here anymore: Foreign language learning and renegotiated identity. In A. Pavlenko \& A. Blackledge (eds.), Negotiation of identities in multilingual context. Clevedon, UK: Multilingual Matters, 219-242.

Kinginger, C., \& Belz, J. A. 2005. Sociocultural perspectives on pragmatic development in foreign language learning: Case studies from telecollaboration and study abroad. Intercultural Pragmatics 2(4), 369-421.

Lam, E. 2000. L2 Literacy and the design of the self: a case study of a teenager writing on the Internet. TESOL Quarterly 34 (3), 457-482. 
Le Page, R. B. \& A. Tabouret-Keller 1985: Acts of identity. Creole-based approaches to language and ethnicity. Cambridge: Cambridge University Press.

Leppänen, S. \& T. Nikula. 2007. Diverse uses of English in Finnish society:

Discourse-pragmatic insights into media, education and business contexts. Multilingua, $26(4), 333-380$.

Mauranen, A. and M. Metsä-Ketelä. 2006. Introduction: English as A Lingua Franca. Nordic Journal of English Studies, 5(2), http://hdl.handle.net/2077/3146

McKay, S. and S. Wong 1996. Multiple discourses, multiple identities: investment and agency in second-language learning among Chinese adolescent immigrant students. Harvard Educational Review 66 (3), 577-608.

Murphey, T., C. Jin and C. Li-Chi 2004. Learners' construction of identities and imagined communities. In P. Benson and D. Nunan (eds.), Learners' stories. Difference and diversity in language learning. Cambridge: Cambridge University Press, 83-100.

Norton, B. 2000. Identity and language learning. Gender, ethnicity and educational change. Harlow: Pearson Education Ltd.

Norton, B. and K. Toohey. 2002. Identity and language learning. In R.B. Kaplan (ed.), The Oxford handbook of Applied Linguistics. Oxford: Oxford University Press, 115-123.

Omoniyi, T. and G. White. 2006. The sociolinguistics of identity. London, New York: Continuum.

Pavlenko, A. 2003. "I never knew I was a bilingual": reimagining teacher identities in TESOL. Journal of Language, Identity, and Education [online], 2 (4), 251-268. (accessed 25 Aug 2006) http://search.epnet.com/login.aspx?direct=true \&db=ufh\&an=11472756

Pavlenko, A. and A. Blackledge (eds.) 2004. Negotiation of identities in multilingual contexts. Clevedon: Multilingual Matters.

Pellegrino, V. 1998. Student perspectives on language learning in a study abroad context. Frontiers: The Interdisciplinary Journal of Study Abroad [online], 4, (accessed 28 Aug 2006) http://www.frontiersjournal.com/issues/vol4/vol4-04 Pelligrino.htm

Polanyi, L. 1995. Language learning and living abroad. Stories from the field. In B. Freed (ed.) Second language acquisition in a study abroad context. Amsterdam: John Benjamins Publishing Company, 271-291.

Pomerantz, A. 2001. Beyond the good language learner: ideology, identity, and investment in classroom foreign language learning. Unpublished Doctoral Dissertation. University of Pennsylvania, Department of Educational Linguistics. 
Pölzl, U. 2003. Signalling cultural identity: the use of L1/Ln in ELF. ViennaEnglish Working papers [online], 12 (2), 3-24. (accessed 19 Nov 2005) http://www.univie.ac.at/Anglistik/ang_new/online papers/views/03_2/POELSGL.PDF

Rampton, B. 2007. Linguistic ethnography and the study of identities. Working Papers in Urban Language and Literacies, 43, Kings College London.

Seidlhofer, B. 2001. Closing a conceptual gap: the case for a description of English as a lingua franca. International Journal of Applied Linguistics 11 (2), 133-158.

Seidlhofer, B. 2003. A Concept of international English and related issues: From 'real' English' to 'realistic English'? Strasbourg: Council of Europe.

Seidlhofer, B. 2004. Research perspectives on teaching English as a lingua franca, Annual Review of Applied Linguistics 24, 209-239.

Seidlhofer, B. 2006. English as a Lingua Franca in the expanding circle: what it isn't. In R. Rudby and M. Saraceni (eds.), English in the World: Global Rules, Global Roles. London: Continuum, 40-50.

Thesen, L. 1997. Voices, discourse, and transition: in search of new categories in EAP. TESOL Quarterly 31 (3), 487-511.

Virkkula, T. 2006. Stay abroad and foreign language users' identity construction. Unpublished Pro Gradu Thesis, University of Jyväskylä. http://urn.fi/URN:NBN:fi:jyu-2006600

Weedon, C. 1997 (1987). Feminist practice and poststructuralist theory. Oxford: Blackwell Publishing.

Woodward, K. (ed.) 1997. Identity and difference. London: Sage. 